\title{
A Recurrent Translocation, t(3;11)(q21;q13), Found in Two Distinct Cases of Acute Myeloid Leukemia
}

\author{
Juan C. Cigudosa, M. José Calasanz, M. Dolores Odero, \\ Julián Marin, Enrique Bengoechea, and Arturo Gullón
}

\begin{abstract}
We report two cases of acute myeloid leukemia (M1 and M5B subtypes) with a similar translocation, $t(3 ; 11)(q 21 ; q 13)$. We discuss the involvement of these breakpoints in acute leukemia and their putative clinical implications.
\end{abstract}

\section{INTRODUCTION}

Karyotypes with single chromosomal rearrangements involving band q13 of chromosome 11 are a quite rare finding in acute myeloid leukemia (AML) and are associated with cases of M4 and M5 FAB subtypes [1, 2]. Rearrangements of the long arm of chromosome 3 affecting bands q21-q26 have been reported both in cases associated with an abnormal thrombopoiesis [3-5] and in cases lacking such an association [6, 7]. The joining of both events, that is, rearrangements involving breakpoints 3q26 and 11q13, has been recently described in a case of M4 AML [2]. We report two cases of AML with a reciprocal translocation between chromosomes 3 and 11 with breakpoints at bands q21 and q13, respectively.

\section{PATIENTS AND METHODS}

\section{Patient 1}

A 58-year-old woman was admitted to the hospital in August 1993 because of asthenia and anorexia during the last month. Physical examination revealed pallor and gingival hypertrophy. Blood findings were $17.8 \times 10^{9} / \mathrm{L}$ white blood cell (WBC) count ( $56 \%$ of atypical monocytes and $2 \%$ blasts), hemoglobin $10.1 \mathrm{~g} / \mathrm{dL}$, and platelet count $67 \times 10^{9} / \mathrm{L}$. After morphologic examination of bone marrow aspirate, a diagnosis of acute nonlymphocytic leukemia of the FAB subtype M5 B was made. Immunologic markers were as follows: CD45 (100\%), CD14 (40\%), HLA-DR (90\%), CD13 (67\%), CD33 (91\%), CD56 (53\%), and CD16 (16\%). A complete remission

From the Department of Genetics (M. J. C., M. D. O., A. G.), University of Navarra, Pamplona; Service of Hematology (J. M., E. B.), Hospital N. Sra de Aranzazu, San Sebastián; and Service of Cytogenetics (J. C. C.), Faculty of Medicine, University of La Laguna, Canary Islands, Spain.

Address reprint requests to: Dr. J. C. Cigudosa, Servicio de Citogenética, Facultad de Medicina, Universidad de La Laguna, 38071 La Laguna, Tenerife, Spain.

Received August 25, 1994; accepted January 24, 1995. was induced after $3 \times 7$ cycles of treatment with daunoblastin and cytarabine, and the patient now remains asymptomatic.

\section{Patient 2}

A 22-year-old man was admitted to the hospital in November 1993 because of pallor. Blood cell counts were $3.4 \times$ $10 \% / \mathrm{L}$ WBC count ( $40 \%$ of blasts), hemoglobin $7.4 \mathrm{~g} / \mathrm{dL}$, and platelet count $58 \times 10^{9} / \mathrm{L}$. After morphologic examination of bone marrow aspirate, a diagnosis of acute nonlymphocytic leukemia of the FAB subtype M1 was made. Peroxidase was positive for $38 \%$ of blasts, PAS and naftol-acetate-esterase tests were concordant with this diagnosis. A complete remission was induced after $3 \times 7$ cycles of treatment with doxyrubicine and cytarabine, and the patient now remains asymptomatic.

Bone marrow cells were short-term cultured (24-48 hours) and analyzed by standard cytogenetic methods which include Trypsin-Giemsa banding. Samples from both patients were examined at diagnosis, during treatment, and at hematologic remission.

\section{RESULTS}

Patient 1 at diagnosis showed the following karyotype: $46, \mathrm{XX}, \mathrm{t}(3 ; 11)(\mathrm{q} 21 ; \mathrm{q} 13)$ in all 30 observed metaphases. During the treatment we performed a new analysis and we observed 20 metaphases with normal karyotype and 15 metaphases with the same $t(3 ; 11)$ translocation. Once hematologic remission was achieved, a new sample was analyzed and we saw only normal cells, confirming the remission also at the cytogenetic level.

Patient 2 had a similar cytogenetic story. At diagnosis, 10 cells showed a normal karyotype and 15 cells showed the following karyotype: $46, \mathrm{XY}, \mathrm{t}(3 ; 11)(\mathrm{q} 21 ; \mathrm{q} 13)$. During the treatment the proportion of normal cells increased ( 20 normal cells, 10 cells with the translocation), and finally, when hematologic remission was induced only normal cells were seen. Partial karyotypes of both cases are shown in Figure 1. 
A

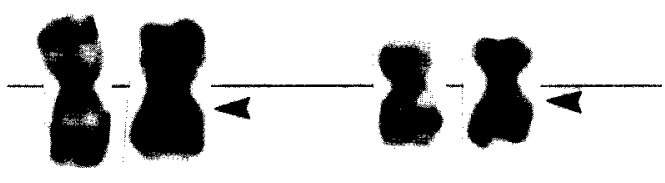

B

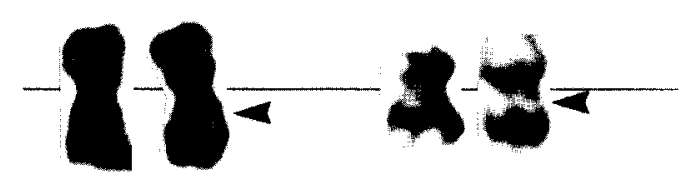

3

Figure 1 Partial karyotype of patients 1 (A) and 2 (B) with a similar $t(3 ; 11)(q 21 ; q 13)$ translocation. Arrowheads show the involved breakpoints.

\section{DISCUSSION}

From the cytogenetic point of view, two aspects are of interest in this report. Firstly the fact that in both cases, despite the presence of rearrangements of band 3q21, abnormal megakaryopoiesis was not demonstrable. Thus, the proposed association between breakpoints at 3q21 and $3 q 26$ and that feature [3-5] might be restricted either to the distal breakpoint or to the simultaneous involvements of both chromosomal segments. We agree with the suggestion of Kwong et al. (1993) about this relationship: rearrangements of 3q26 (3q21 in our case) may play an important role in leukemogenesis and may or may not affect different candidate genes, with one (some) associated with abnormal thrombopoiesis. On the other hand, the involvement of band 11q13 is not a common finding in AML, however, its recurrence in M4 and M5 FAB subtypes should be considered for the future. The molecular references for this segment tell us nothing about the role in leukemogenesis in the two genes so far mapped within it $[8,9]$. These genes (named BCL-1 and PRAD1) are clearly involved in lymphomagenesis but nothing is known about their importance in AML.

Our patients were classified as having M5 B (Patient 1) and M1 (Patient 2) AML. Thus the translocation does not seem to be very specific for a determinate subtype of AML. However, taking together all the reported cases with single chromosomal rearrangements of 11q13, including one of our cases, it is relevant that they correspond to either the M4 or the M5 subtype $[1,2]$. If there is a new subset of AML associated with this type of rearrangement it is still not clear, but waits yet to be determined.

\section{REFERENCES}

1. Mitelman F, (1991): Catalog of Chromosome Aberrations in Cancer. Fourth Edition. Wiley Liss, New York.

2. Kwong YL, Lie AKW, Chan LC (1993): A novel translocation $(3 ; 11)(q 26 ; q 13)$ in a case of acute myelomonocytic leukemia. Cancer Genet Cytogenet 69:158-160.

3. Bitter MA, Neilly ME, Le Beau MM, Pearson MG, Rowley JD (1985): Rearrangements of chromosome 3 involving bands 3q21 and 3q26 are associated with normal or elevated platelet counts in acute nonlymphocytic leukemia. Blood 66:1362-1370.

4. Heim S and Mitelman F (1987): Cancer Cytogenetics. New York, Alan R. Liss, Inc., pp 81-85.

5. Jotterand Bellomo M, Parlier V, Muhlemamatter D, Grob JP, Beris PH (1992): Three new cases of chromosome 3 rearrangements in bands q21 and q26 with abnormal thrombopoiesis bring further evidence to the existence of a 3q21q26 syndrome. Cancer Genet Cytogenet 59:138-160.

6. Raimondi SC, Dube ID, Valentine MB, Miro J, Jim Watt H, Larson RA, Bitter MA, LeBeau MM, Rowley JD (1989): Clinicopathologic manifestations and breakpoints of the $t(3 ; 5)$ in patients with acute nonlymphocytic leukemia. Leukemia 3:42-47.

7. Rubin CM, Larson RA, Anastasi J, Winter JN, Thangavelu M, Vardiman JW, Rowley JD, Le Beau MM (1990): $\mathrm{t}(3 ; 21)$ (q26; 222 ): a recurring chromosomal abnormality in therapy-related myelodysplastic syndrome and acute myeloid leukemia. Blood 76:2594-2598

8. Tsujimoto Y, Yunis J, Onorato-Showe L, Erikson J, Nowell PC, Croce CM (1984): Molecular cloning of the chromosomal breakpoint of B-cell lymphomas and leukemias with the $t(11 ; 14)$ chromosome translocation. Science 224:1403-1406.

9. Motokura T, Bloom T, Kim HG, Jupner H, Ruderman JV, Kronenberg HM, Arnold A (1991): A novel cyclin encoded by a bcl-1 linked candidate oncogene. Nature 350:512-515. 